\title{
Self-tuning Fuzzy Logic Controller Based on Takagi-Sugeno Applied to Induction Motor Drives
}

\author{
Nabil Farah, M. H. N. Talib, Z. Ibrahim, J. M. Lazi, Maaspaliza Azri \\ Faculty of Electrical Engineering, Center for Robotics and Industrial Automation (CeRIA), Universiti Teknikal Malaysia \\ Melaka, Malaysia
}

\begin{tabular}{|c|c|}
\hline Article Info & ABSTRACT \\
\hline & \multirow{9}{*}{$\begin{array}{l}\text { Fuzzy logic controller has been the main focus for many researchers and } \\
\text { industries in motor drives. The popularity of Fuzzy Logic Controller (FLC) is } \\
\text { due to its reliability and ability to handle parameters changes during load or } \\
\text { disturbance. Fuzzy logic design can be visualized in two categories, } \\
\text { mamdani design or Takagi-Sugeno (TS). Mamdani type can facilitate the } \\
\text { design process, however it require high computational burden especially with } \\
\text { big number of rules and experimental testing. This paper, develop Self- } \\
\text { Tuning (ST) mechanism based on Takagi-Sugeno (TS) fuzzy type. The } \\
\text { mechanism tunes the input scaling factor of speed fuzzy control of Induction } \\
\text { Motor (IM) drives Based on the speed error and changes of error. A } \\
\text { comparison study is done between the standard TS and the ST-TS based on } \\
\text { simulations approaches considering different speed operations. Speed } \\
\text { response characteristics such as rise time, overshoot, and settling time are } \\
\text { compared for ST-TS and TS. It was shown that ST-TS has optimum results } \\
\text { compared to the standard TS. The significance of the proposed method is } \\
\text { that, optimum computational burden reduction is achieved. }\end{array}$} \\
\hline Received Aug 8, 2018 & \\
\hline Revised Sep 21, 2018 & \\
\hline Accepted Oct 10, 2018 & \\
\hline Keyword: & \\
\hline Computational burden & \\
\hline IM drive & \\
\hline ST-TS & \\
\hline TS & \\
\hline
\end{tabular}

Copyright @ 2018 Institute of Advanced Engineering and Science.

\section{Corresponding Author:}

Nabil Farah,

Faculty of Electrical Engineering,

Center for Robotics and Industrial Automation (CeRIA),

Universiti Teknikal Malaysia Melaka, Melaka, Malaysia

Email: Nabil-farah11@hotmail.com

\section{All rights reserved.}

\begin{abstract}
\end{abstract}
-

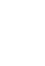


while the TS fuzzy applied to the tuning mechanism. The system utilizes TS fuzzy with 25 rules to achieve better performance and reduce the computational burden on the hardware.

There is a lack of studies of utilizing the TS type as speed control of induction motor drive and tune it with the same TS type. However, a study [17] has proposed a self-tuning ST based on TS fuzzy type for process performance improvement. The study has discussed in general the implementation of Self-Tuning Takagi-Sugeno (ST-TS) to tune a Takagi-Sugeno fuzzy type considering a general process system. However, the proposed system applied to the First Order and Second order with delay time transfer function. The effectiveness of the proposed controller applied to the higher order system such as IM drive system is still undiscovered.

This paper aims to utilize the features of TS fuzzy type in reducing the computational burden. The TS fuzzy type are applied to the main speed controller and Self-Tuning mechanism. The Self-tuning mechanism is used to tune fuzzy the input scaling factors. Any variation of on the speed error will be compensated by the ST mechanism to update the scaling factors to adapt to the system variations. This approached is aimed to achieve optimum computational burden reduction achieved and beneficial especially for real experimental test.

The paper divided into five sections, section I review the fuzzy logic control in IM drive system and discusses the effectiveness of TS fuzzy type. Section II, presents the mathematical modelling of the IM drive system along with associated equations. Section III focus on the design producers of Takagi -Sugeno (TS) as well as the Self-Tuning Takagi-Sugeno (ST-TS) along with corresponding membership functions and rule bases. Section IV presents the simulations results of comparison between the Standard TS fuzzy and the selftuned ST-TS fuzzy. Lastly, section V conclude the of the study and highlighted the main finding obtained.

\section{INDUCTION MOTOR MODEL}

The induction motor is mathematically modelled and can be represented in various reference frame. Different references frame of induction motor is discussed in [18], [22]. Figure 1 shows the simplified equivalent q-axis and d-axis circuit of squirrel cage induction motor in rotary reference frame [20].

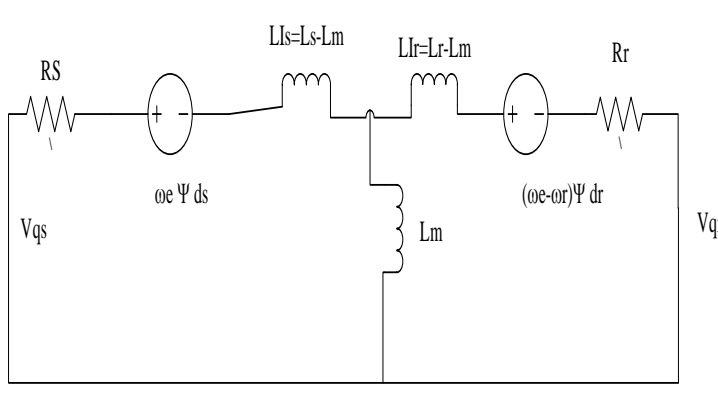

(a)

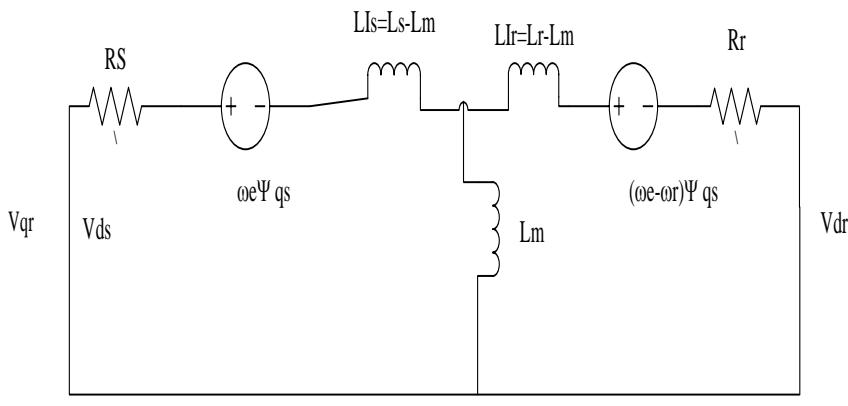

(b)

Figure 1. Equivalent circuit of induction motor in rotary reference frame (a) q-axis frame, (b) d-axis frame

Referring to the equivalent circuit of induction motor represented in Figure 1, voltage in q-axis and $\mathrm{d}$-axis of rotor and stator can be expressed as follow:

$$
\begin{aligned}
& \psi_{d r}=L_{l r} i_{d r}+L_{m}\left(i_{d s}+i_{d r}\right) \\
& V_{q s}=R_{s} i_{q s}+\frac{d \psi_{q s}}{d t}+\omega_{e} \psi_{d s} \\
& V_{d s}=R_{s} i_{d s}+\frac{d \psi_{d s}}{d t}+\omega_{e} \psi_{d s}
\end{aligned}
$$




$$
\begin{aligned}
& V_{q r}=R_{r} i_{q r}+\frac{d \psi_{q r}}{d t}+\left(\omega_{e}-\omega_{r}\right) \psi_{d r} \\
& V_{d r}=R_{r} i_{d r}+\frac{d \psi_{d r}}{d t}+\left(\omega_{e}-\omega_{r}\right) \psi_{q r}
\end{aligned}
$$

And $V_{q r}, V_{d r}=0$ and the flux equation as follow:

$$
\begin{aligned}
& \psi_{q s}=L_{l s} i_{q s}+L_{m}\left(i_{q s}+i_{q r}\right) \\
& \psi_{q r}=L_{l r} i_{r}+L_{m}\left(i_{q s}+i_{q r}\right) \\
& \psi_{d s}=L_{l s} i_{d s}+L_{m}\left(i_{d s}+i_{d r}\right)
\end{aligned}
$$

The electromagnetic torque can be expressed as follow:

$$
T_{e}=\frac{3}{2} \frac{P}{2} \frac{L_{m}}{L_{r}}\left(\psi_{d r} i_{q s}-\psi_{q r} i_{d s}\right)
$$

The number of induction motor poles is represented by $\mathrm{P}$, once the vector control is achieved $\mathrm{d}$ frame of rotor side is zero. Hence, the motor torque is controlled by q frame of stator side as modelled in equation 10:

$$
T_{e}=\frac{3}{2} \frac{P}{2} \frac{L_{m}}{L_{r}}\left(\psi_{d r} i_{q s}\right)
$$

The full drive system of induction motor is presented in Figure 2. The system consists of speed controller, phase conversion, hysteresis current controller, inverter, motor and encoder.

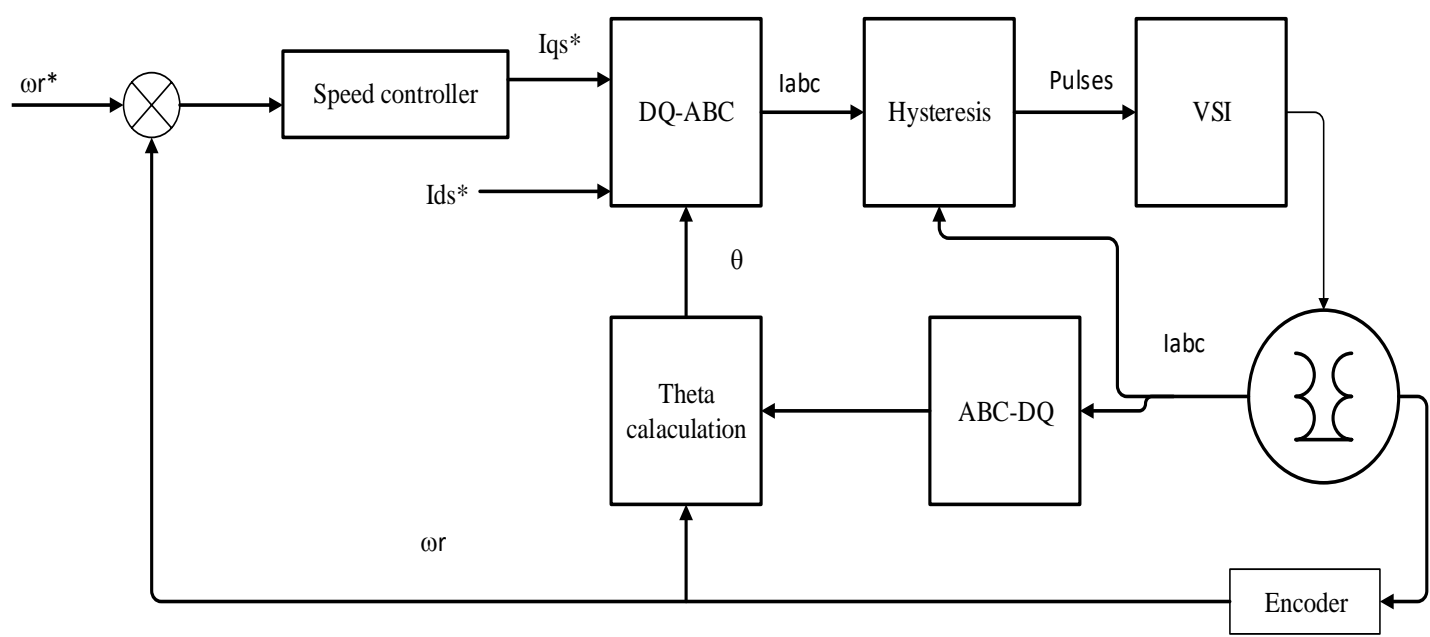

Figure 2. Induction motor drive based Hysteresis current controller

The FOC drive system presented in Figure 2 is based on hysteresis current controller [21]. This is due to its simple structure, fast response and good accuracy. The inverter pulses are generated by utilizing hysteresis band. The speed controller is designed using fuzzy logic controller. The speed error between actual motor speed and reference speed are processed through speed controller to produce the torque current reference current $\mathrm{iq}^{*}$. The $\mathrm{iq}^{*}$ current is gathered with constant $\mathrm{id}^{*}$ and transformed into three phase quantities. These three phase quantities are the reference currents which are then compared with the three

Self-tuning Fuzzy Logic Controller Based on Takagi-Sugeno Applied to Induction Motor... (Nabil Farah) 
phase actual motor currents. The resultant of the comparison between the actual and reference currents is then fed into hysteresis current controller to generate the required switching pulses for the three phase Voltage Source Inverter (VSI)[19], [23].

\section{SPEED CONTROLLER DESIGN}

The fuzzy logic controller utilized as speed control which take two input (error and change of error) and process them to produce the output signal .There are three steps in fuzzy logic controller, fuzzification which convert the crisp data into fuzzy data or MF. Interface engine will combine the MFs with designed fuzzy rules to obtain the fuzzy output. Lastly the defuzzification will convert back the fuzzy data into crisp output data. Figure 3 shows the block diagram of fuzzy logic controller steps. There are two type of fuzzy interface system (FIS), mamdani or Takagi-Sugeno (TS). TS fuzzy applied a singleton MFs for the output fuzzy. The advantages of this TS fuzzy type self-tuning controller are to reduce the computational burden of the controller. In the following section, the design process for ST mechanism will be further discussed.

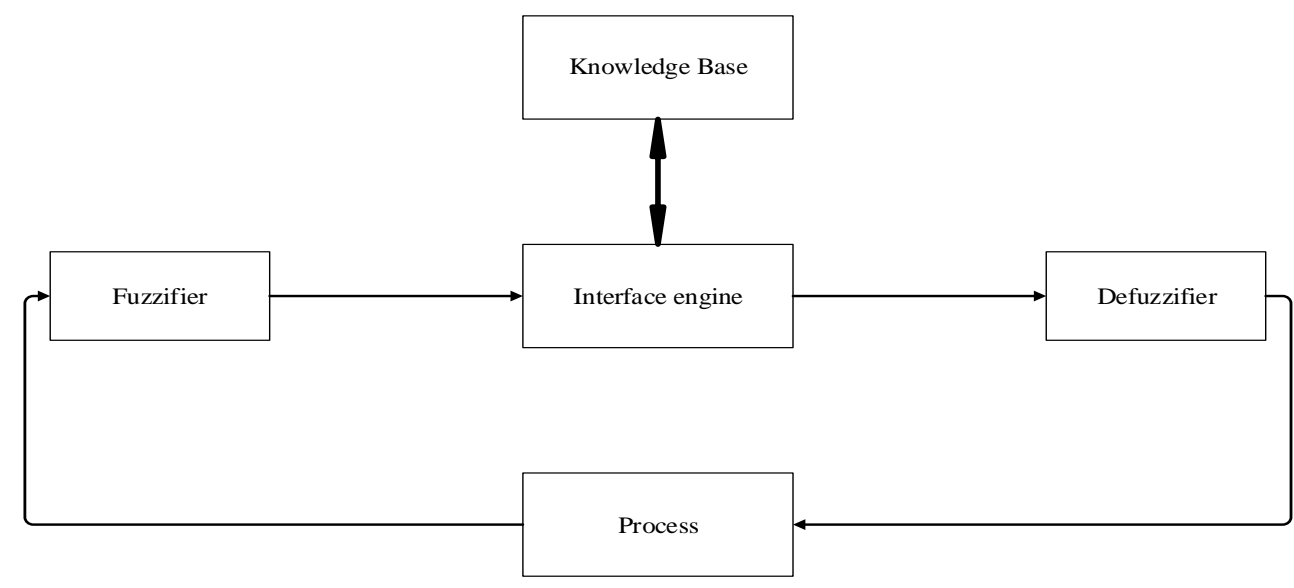

Figure 3. Fuzzy logic block diagram

\subsection{Standard Takagi-Sugeno (TS) Design}

The standard TS is same as mamdani type for the input variables. For induction motor two inputs fuzzy with linear MFs and one output fuzzy with constant MFs. For each input and output there is a scaling factor to adjust the factor. Figure 4 presents the block diagram of fuzzy logic controller utilized for speed control of induction motor. Two input variables speed error (e) and change of speed error $(\Delta \mathrm{e})$ which need to be converted into fuzzy variables (fuzzification), then the interface engine combines the fuzzy rules with the MFs of the variables to produce the fuzzy output. The defuzzification process convert back the fuzzy variables to crisp variables utilizing fuzzy rules and singleton output MFs.

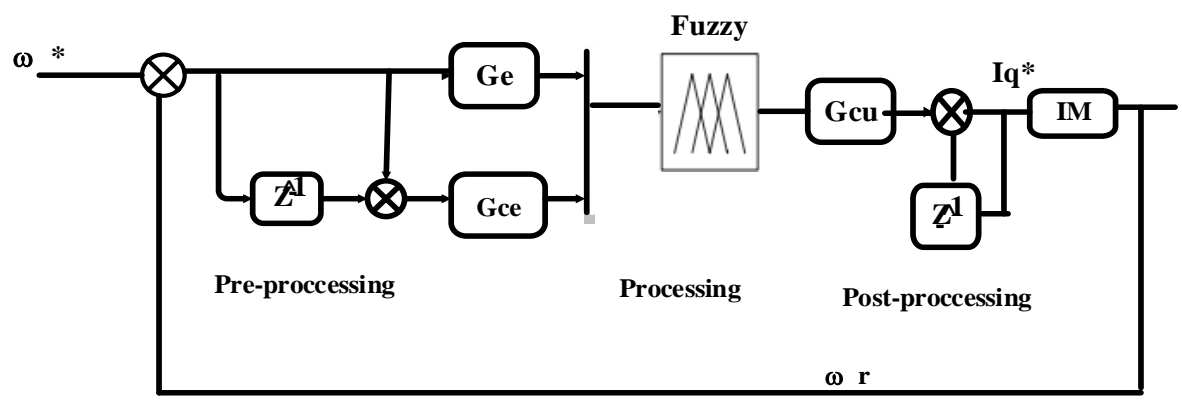

Figure 4.Standard TS for IM drive

In the preprocessing part, the crisp inputs of the speed error, e and its change of speed error $\Delta \mathrm{e}$ are converted into to their corresponding fuzzy variable and they are defined as: 


$$
\begin{aligned}
& e(k)=G_{e}\left(\omega_{r}{ }^{*}(k)-\omega_{r}(k)\right)=G_{e}(k) \\
& \Delta e(k)=G_{c e} \frac{(e(k)-e(k-1)}{T_{S}}
\end{aligned}
$$

From the above equation, $\omega r *$ and $\omega r$ stand for reference and actual speed respectively. Meanwhile, (k) and (k-1) represent the current and previous state of the error. Ts represents for the sampling time. The Ge and Gce denote the error and the change of error gain scaling factor. The maximum Ge gain is determined to cover the rated speed using the following equation.

$$
G_{e}=\frac{1}{\left|\omega_{e \max }\right|}
$$

Where, $\omega_{e}$ max is the maximum error for the rated speed operation to ensure high enough gain applied to cover the rated speed operation and normalized the input value. For the change of error gain, Gce and output gain, Gcu the membership function range opted to fit the rated speed operation. The membership function for error (e) and change of error $\Delta \mathrm{e}$ and incremental output gain, cu are presented in Figure 5. Seven membership functions are utilized for the inputs e and $\Delta \mathrm{e}$ while 7 singleton membership functions are utilized for the output. Universe of discourse for input is decomposed into seven fuzzy MFs for input ranging from Negative Big (NB) into Positive Big (PB). While for the output seven singletons (constant) MFs are selected which implies the feature of Takagi-Sugeno (TS), fuzzy type. This can minimize the execution time of the fuzzy system.

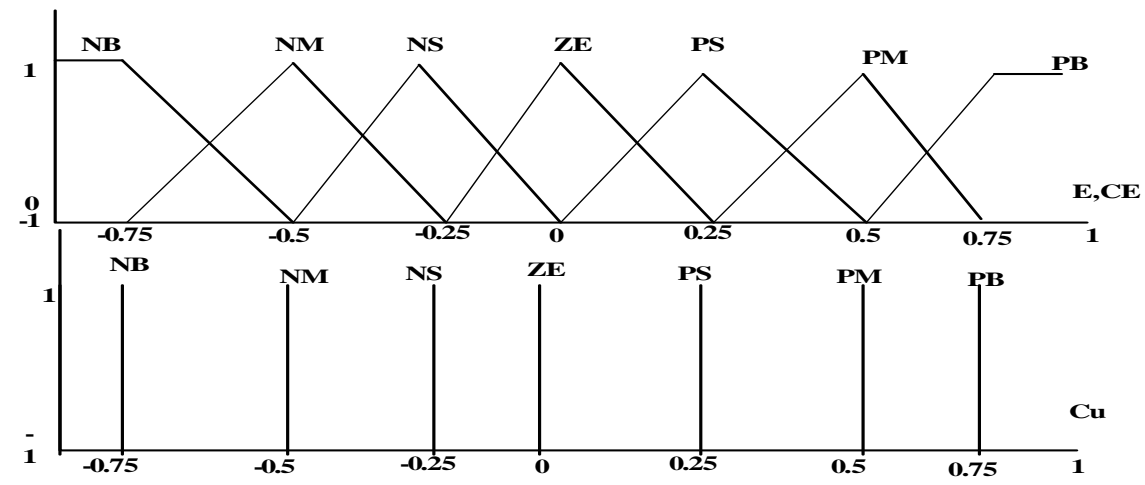

Figure 5. Inputs and output membership functions variable design 49 rules

The 7x7 mambership functions matrix results in 49 fuzzy rule set. The fuzzy rules sets designed are presented in Table 1 for 49 rules. The rules are developed using TS-type fuzzy inference. The rules are interpreted based on the tables for the rules design using Fuzzy Logic Tools Matlab.

Table1. Fuzzy Rule (49)

\begin{tabular}{cccccccc}
$\nabla \mathrm{C}$ & \multirow{2}{*}{ NB } & \multirow{2}{*}{ NM } & \multirow{2}{*}{ NS } & ZE & PS & PM & \multirow{2}{*}{ PB } \\
\hline NB & NB & NB & NB & NB & NM & NS & ZE \\
NM & NB & NB & NB & NM & NS & ZE & PS \\
NS & NB & NB & NM & NS & ZE & PS & PM \\
ZE & NB & NM & NS & ZE & PS & PM & PB \\
PS & NM & NS & ZE & PS & PM & PL & PB \\
PM & NS & ZE & PS & PM & PB & PL & PB \\
PB & ZE & PS & PM & NB & PB & PB & PB \\
\hline
\end{tabular}

Through defuzzification, the output current $\mathrm{Iq}^{*}$ is calculated using the following equation

$$
I^{*}{ }_{q}(k)=I *_{q}(k-1)+G c u(\Delta I q(k))
$$

The scaling factor for the fuzzy designed are manually tuned to obtain the optimum performance for the Gce value. While Ge value is constant based on the maximum speed error calculation. Lastly, the Gcu value is set to 1 . 


\subsection{Self-Tuned ST Design (ST-TS)}

The previous section discussed the design process of standard TS fuzzy or fixed gains fuzzy. It was observed that the value of output gain $(\mathrm{Gcu})$ is fixed which make the system unable to adapt online with any changes occurs. The proposed Self-Tuning mechanism (ST-TS) focused on tuning the input scaling factors which enable the input scaling factors Ge and Gce to adapt online in accordance to the process changes for performance improvement. Two fuzzy system have been designed to tune the inputs scaling factor. Figure 6 presents the block diagram of the proposed self-tuning mechanism.

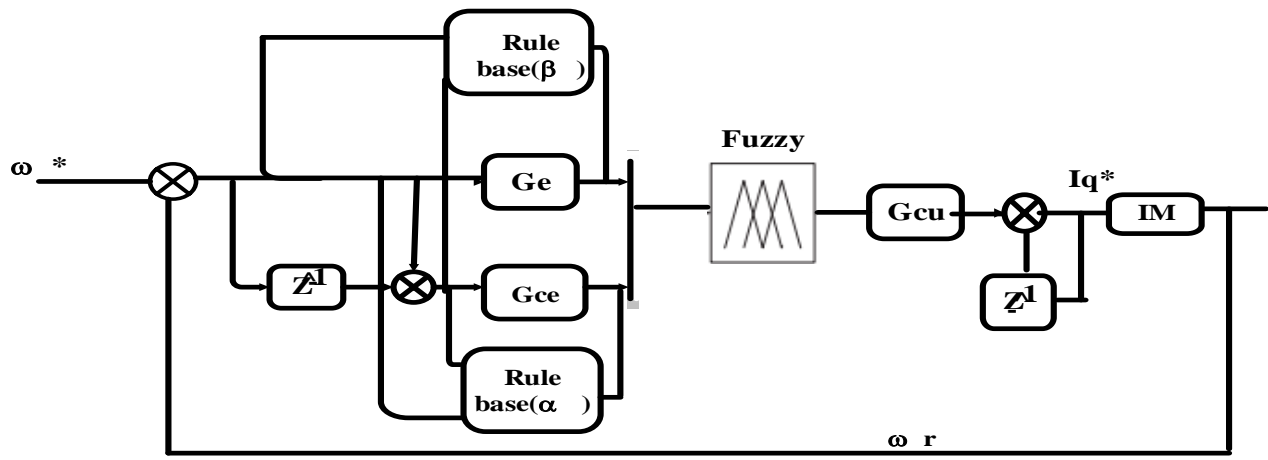

Figure 6. Proposed Self-Tuning (ST_TS) mechanism

As discussed earlier, the proposed ST-TS to tune the inputs scaling factors by designing the rules defined in terms of e and Ce for updating the scaling factors. Self-tuning method basically means that the self-tuning of input gains based on error and change in error. According to this ST mechnasim, the input scaling factors can be computed by utilizing the following equations:

$$
\begin{aligned}
& \mathrm{E}(\mathrm{k})=(\alpha \cdot \mathrm{Ge}) \cdot \mathrm{e}(\mathrm{k}) \\
& \mathrm{Ce}(\mathrm{k})=(\beta \cdot \mathrm{Gce}) \Delta \mathrm{ek})
\end{aligned}
$$

$\alpha$ and $\beta$ are the updating factors which used to continuously adjust the inputs scaling factors Ge and Gce based on the errors and change of errors. Hence, the inputs scaling factors are varied and adjusted online with any changes to the system accordingly. The membership function for $\alpha$ and $\beta$ are presented in Figure 7 .

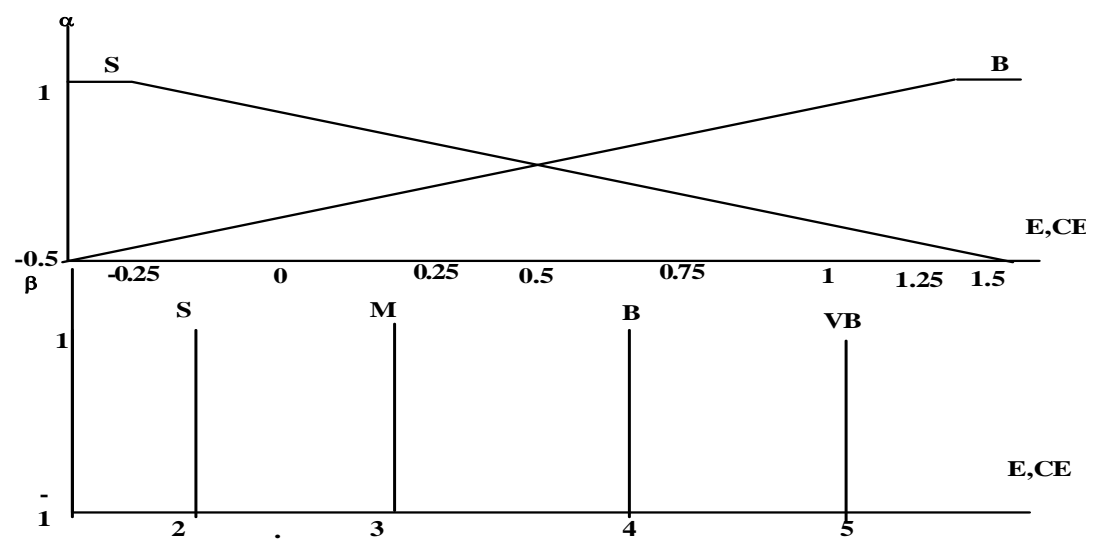

Figure 7. Membership function for updating factors $\alpha, \beta$

\section{SIMULATION RESULTS}

MATLAB/SIMULINK environment has been utilized to develop the fuzzy system as well as to model the IM drive system. Two different algorithms have been designed which the standard Takagi- Sugeno (ST) and Self-Tuning Takagi-Sugeno (ST-TS). Both methods tested under different speed operations and subjected to load. 49 rules fuzzy were utilized through all the testing .The advantage of ST-TS is producing 
lesser computational burden utilized due to the singleton output membership functions. In addition, ST-TS system is able to increase the accuracy of the system performance.

\subsection{No-load Operations}

The speed performance of TS and ST at 400,900 and $1400 \mathrm{rpm}$ with no load is presented in Figure $8,9,10$ respectively. The selected speed ranges cover from low to rated speed operations.

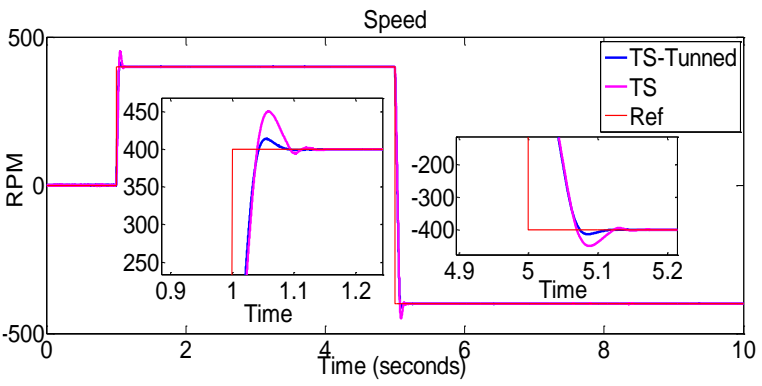

Figure 8.Speed response at 400rpm

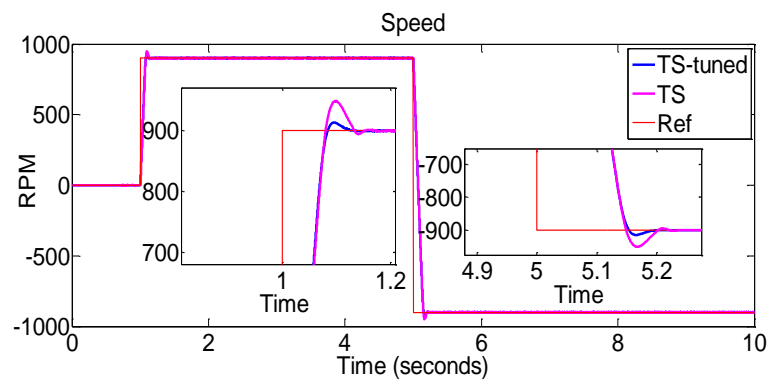

Figure 9. Speed response at 900rpm

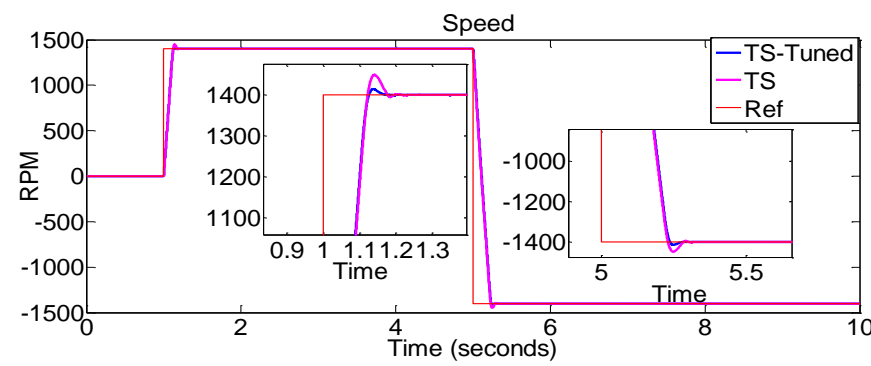

Figure 10.Speed response at 1400rpm with close up view

Figure 11 shows the phase A output current for the both controllers at $1400 \mathrm{rpm}$ with maximum current at starting 10A. In addition, the torque output of TS and ST-TS are compared and presented in Figure 12 , in which the ST-TS is better than TS with lesser torque ripple. Both torque and current performance shown typical correlation between torque, current and speed bahaviour of motor drive system. Thus, validated the simulation system developed.The performance analysis for the two algorithms in terms of rise time, settling time and overshoot for the speed response in reverse and forward operation is presented in Table 2. The speed performance analysis shows that, ST-TS is superior in term of rise time, settling time as well as percent overshoot. The ST-TS overshoot with only $15 \mathrm{rpm}$ beyond the reference while TS overshoot with $49 \mathrm{rpm}$ beyond the reference.

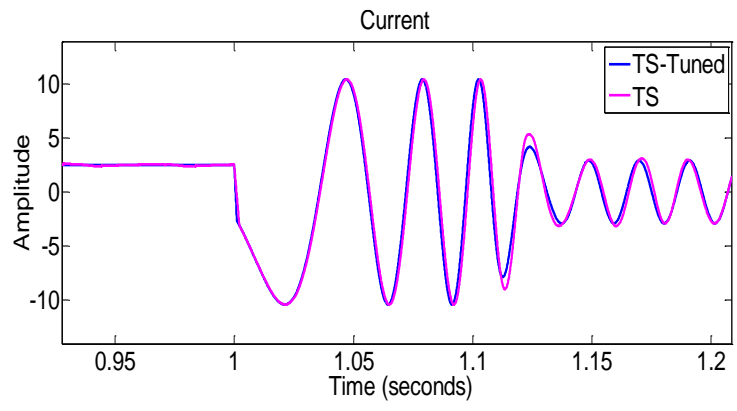

Figure 11. Output of phase a current

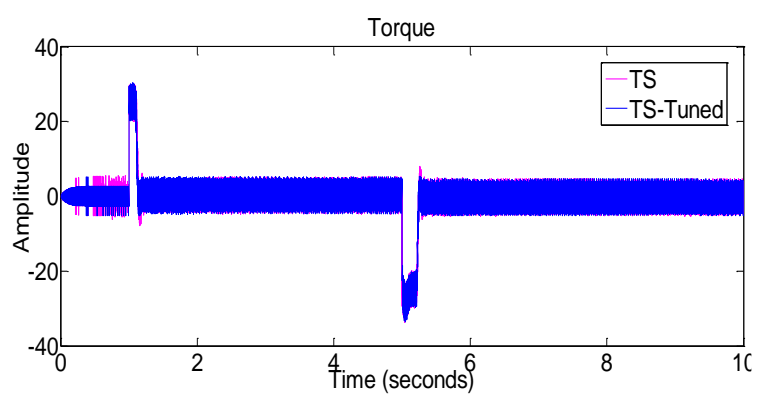

Figure 12. Torque output 


\subsection{Loaded Operation}

A load was applied to the system to observe the reliability of the controllers and their stability to changes in terms of speed, currents as well as torque produced. The speed response at $1400 \mathrm{rpm}$ with load applied is presented in Figure 13.

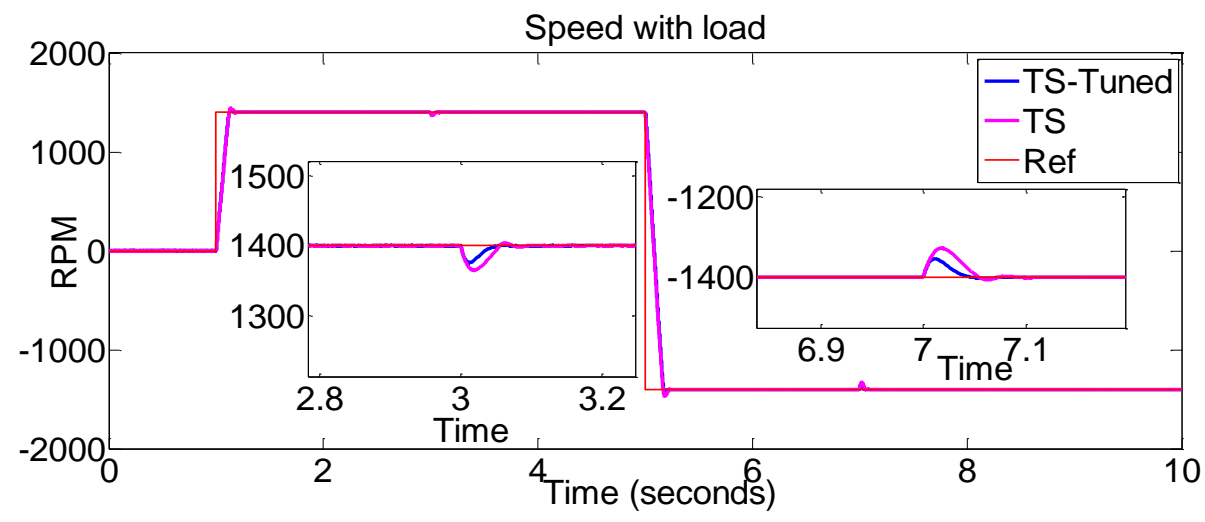

Figure 13. Speed response at 1400rpm with load

The ST-TS speed has speed drop of $24 \mathrm{rpm}$ in $0.51 \mathrm{~s}$ before return to its steady state condition, while the TS speed dropped is $35 \mathrm{rpm}$ with recovery time of 0.56s. The phase A output currents and torques during load are presented in Figures 14 and 15 respectively.

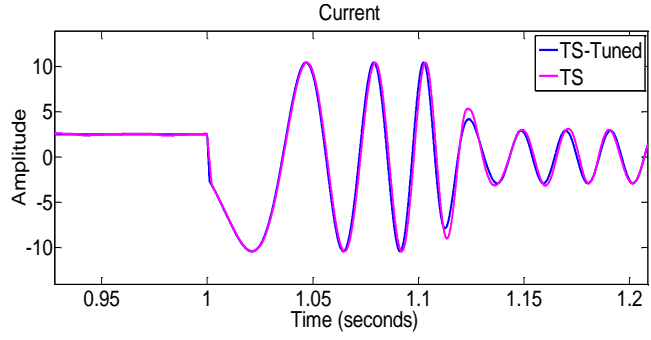

Figure 14.Currents response with load

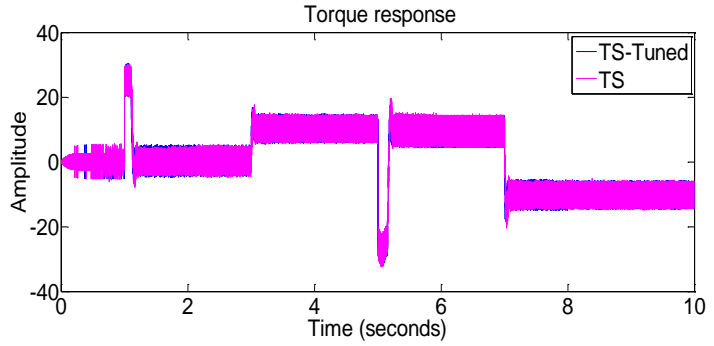

Figure 15.Torques response with load

\section{CONCLUSION}

In conclusion, this paper presented a comparative study between standard fuzzy logic and Selftuning fuzzy logic based on Takagi-Sugeno fuzzy interface type applied to the speed control of induction motor drive. Takagi-Sugeno (TS) is fuzzy type that utilizes singleton output membership function and reduces the fuzzy computational burden. Speed, torque and currents performance have been compared for two controllers in terms rise, settling time and percent overshoot. In all cases, ST-TS controller showed superior performance due to its ability to adjust the input scaling factors online in accordance to variations in speed error and change of speed error of the system.

\section{APPENDIX A: INDUCTION MOTOR PARAMETERS}

Vs $\quad($ rated $)=380 \mathrm{~V}, \mathrm{fs}($ rated $) \quad=50 \mathrm{~Hz}, \mathrm{P}($ poles $)=4, \omega \mathrm{r} \quad($ rated $)=1400, \mathrm{Rs}=3.45, \quad \mathrm{Rr}=3.6141, \quad \mathrm{Ls}=0.3252 \mathrm{H}$, $\mathrm{Lr}=0.3252 \mathrm{H}, \mathrm{Lr}=0.3117 \mathrm{H}, \mathrm{J}=0.3252 \mathrm{H}=0.02 \mathrm{kgm}^{\wedge} 2$

\section{ACKNOWLEDGMENTS}

The authors would like to gratefully acknowledge the funding support provided by UTeM and the Ministry of Education Malaysia under the research grant No: FRGS/1/2015/TK04/FKE/02/F00258. 


\section{REFERENCES}

[1] Uddin, M. Nasir, Tawfik S. Radwan, and M. Azizur Rahman. "Performances of fuzzy-logic-based indirect vector control for induction motor drive." IEEE Transactions on Industry Applications 38.5 (2002): 1219-1225.

[2] Barrero, F., et al. "Speed control of induction motors using a novel fuzzy sliding-mode structure." IEEE Transactions on Fuzzy Systems 10.3 (2002): 375-383.

[3] Ab Ghani, Mohd Ruddin, et al. "Investigation Study of Three-Level Cascaded H-bridge Multilevel Inverter." Telkomnika 15.1 (2017): 125.

[4] Ibrahim, Zulkifilie, and Emil Levi. "A comparative analysis of fuzzy logic and PI speed control in highperformance AC drives using experimental approach." IEEE Transactions on Industry Applications 38.5 (2002): 1210-1218.

[5] Sahu, Benudhar, K. B. Mohanty, and Swagat Pati. "A comparative study on fuzzy and PI speed controllers for field-oriented induction motor drive." Modern Electric Power Systems (MEPS), 2010 Proceedings of the International Symposium. IEEE, 2010.

[6] Yongchang, Zhang, and Zhao Zhengming. "Comparative study of PI, sliding mode and fuzzy logic controller for rotor field oriented controlled induction motor drives." Electrical Machines and Systems, 2008. International Conference on. IEEE, 2008.

[7] Bai, Ying, and Dali Wang. "Fundamentals of fuzzy logic control-fuzzy sets, fuzzy rules and defuzzifications." Advanced Fuzzy Logic Technologies in Industrial Applications. Springer London, 2006. 17-36.

[8] Mamdani, Ebrahim H., and Sedrak Assilian. "An experiment in linguistic synthesis with a fuzzy logic controller." International journal of man-machine studies 7.1 (1975): 1-13.

[9] Takagi, Tomohiro, and Michio Sugeno. "Fuzzy identification of systems and its applications to modeling and control." IEEE transactions on systems, man, and cybernetics 1 (1985): 116-132.

[10] Farah, N. S. Y., et al. "Experimental investigation of different rules size of fuzzy logic controller for vector control of induction motor drives." Journal of Fundamental and Applied Sciences 10.6S (2018): 1696-1717.

[11] Talib, M. H. N., et al. "Simplified self-tuning Fuzzy Logic Speed controller for induction motor drive." Power and Energy (PECon), 2016 IEEE International Conference on. IEEE, 2016.

[12] Masiala, Mavungu, et al. "Fuzzy self-tuning speed control of an indirect field-oriented control induction motor drive." IEEE Transactions on Industry Applications 44.6 (2008): 1732-1740.

[13] Kusagur, Ashok, S. F. Kodad, and BV Sankar Ram. "Regular paper Novel design of a Takagi-Sugeno fuzzy strategy for induction motor speed control." J. Electrical Systems 6 (2010).

[14] Lopez-Toribio, C. J., R. J. Patton, and S. Daley. "A multiple model approach to fault-tolerant control using takagisugeno fuzzy modelling: real application to an induction motor drive system." Control Conference (ECC), 1999 European. IEEE, 1999.

[15] Moez, Allouche, et al. "Takagi-Sugeno Fuzzy Control of Induction Motor." Proc. Int. Journal of Electrical and Electronics Engg 2.1 (2009).

[16] Shaukat, Neelofar, et al. "Takagi-Sugeno Fuzzy logic based speed control of Induction Motor." Frontiers of Information Technology (FIT), 2016 International Conference on. IEEE, 2016.

[17] Patil, Neha K., and Bhagsen J. Parvat. "Self Tuning Mechanism using Input Scaling Factors of PI like Fuzzy Controller for Improved Process Performance." International Journal of Advanced Research in Computer Science and Electronics Engineering (IJARCSEE) 2.11 (2013): pp-729.

[18] Brice, C. W., et al. "Reference frames for simulation of electric motors and drives." Proceedings of International Conference on Electric Machines. 2000.

[19] Ab Ghani, Mohd Ruddin, Nabil Farah, and M. R. Tamjis. "Field oriented control of 6/4 SRM for torque ripple minimiaztion." Electrical, Electronics, and Optimization Techniques (ICEEOT), International Conference on. IEEE, 2016.

[20] Talib, Md Hairul Nizam, et al. "Comparison Analysis of Indirect FOC Induction Motor Drive using PI, AntiWindup and Pre Filter Schemes." International Journal of Power Electronics and Drive Systems 5.2 (2014): 219.

[21] Talib, M. H. N., et al. "Hysteresis current control of induction motor drives using dSPACE DSP controller." Power and Energy (PECon), 2016 IEEE International Conference on. IEEE, 2016.

[22] Gaeid, Khalaf Salloum, Hew Wooi Ping, and Haider AF Mohamed. "Simulink representation of induction motor reference frames." Technical Postgraduates (TECHPOS), 2009 International Conference for. IEEE, 2009

[23] Farah, Nabil, et al. "Multilevel Inverter Fed Switched Reluctance Motors (SRMs): 6/4, 8/6 and 10/8 SRM Geometric Types." International Journal of Power Electronics and Drive Systems (IJPEDS) 8.2 (2017). 